\title{
Simultaneous Discrete Intradiploic and Intracerebral Atypical Epidermoid Cysts: Possible Embryological Theories
}

\author{
Ya Lyn Samantha Ang, MBBS, FRCSEd, FAMS ${ }^{1,2^{*} \#, ~ J i a n i ~ S h e r r y ~ L i u, ~ M B B S ~}{ }^{1 \#}$, Chi Long Ho, MD, MMed, \\ MRCS, FRCR, FAMS ${ }^{2,3}$, Cristine Szu Lyn Ding, MBBch Bao, FRCPath ${ }^{4}$ and Jai Prashanth Rao, MBBS, MMed, \\ FRCSEd $^{1,2}$
}

\author{
${ }^{1}$ Department of Neurosurgery, National Neuroscience Institute, Singapore \\ ${ }^{2}$ Duke-NUS Medical School, Singapore \\ ${ }^{3}$ Department of Radiology, Sengkang General Hospital, Singapore \\ ${ }^{4}$ Department of Pathology, Tan Tock Seng Hospital, Singapore

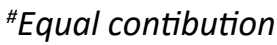

*Corresponding author: Ya Lyn Samantha Ang, MBBS, FRCSEd, FAMS, Department of Neurosurgery, National Neuroscience Institute; Duke-NUS Medical School, Singapore

\begin{abstract}
Epidermoid cysts are benign indolent lesions that account for around $1 \%$ of all primary brain tumours. Embryologically, they are thought to arise from entrapped ectodermal elements during neural tube closure. They often display classic magnetic resonance imaging (MRI) characteristics compared to atypical 'white epidermoids' which display reversed MRI signal intensities. In this article, we describe a 55-year-old lady who presented with progressively worsening headaches and was subsequently found to have simultaneous intradiploic and intracerebral atypical 'white epidermoid' cysts. She underwent craniotomy and excision of the epidermoid lesions. Intraoperatively, there was no apparent communication between the two lesions. We discuss the possible embryological origins and the imaging features as well as the surgical considerations of these atypical epidermoid lesions, including a review of the literature.
\end{abstract}

\section{Keywords}

Epidermoid cyst, Intradiploic, Intracerebral, White epidermoid, Atypical

\section{Introduction}

Epidermoid cysts are benign, slow-growing lesions that account for about $1 \%$ of all primary brain tumours. They commonly occur in the cerebellopontine angle $(40-50 \%)$ and parasellar regions [1,2]. Intraparenchymal or intradiploic epidermoid cysts are rare, accounting for $<5 \%$ of all intracranial epidermoid cysts [3]. Embryologically, epidermoid cysts are thought to arise from entrapped ectodermal elements during neural tube closure.

Epidermoid cysts typically appear on magnetic resonance imaging (MRI) as T1 iso- to hypointense and T2 hyperintense lesions, withthin peripheral enhancement in approximately $25 \%$ of cases [4]. Moreover, they classically show abnormal restricted diffusion with T2 shine-through [5], a feature that helps distinguish it from arachnoid cysts. However, a rare entity known as 'white epidermoid' can display reversed MRI signals with T1 hyper- and T2 hypo-intensities, and rarely, restricted diffusion $[6,7]$. Here, we report a case of a patient with two discrete epidermoid cysts with no apparent connection between them, both displaying unusual imaging and macroscopic features.

\section{Case Report}

A right-handed 55-year-old Chinese lady with a background of hyperlipidemia, bilateral cataracts and previous appendicectomy presented to the hospital with two months of progressively worsening headaches, and three weeks of short-term memory loss and personality

Citation: Ang YLS, Liu JS, Ho CL, Ding CSL, Rao P (2022) Simultaneous Discrete Intradiploic and Intracerebral Atypical Epidermoid Cysts: Possible Embryological Theories. Neurosurg Cases Rev 5:094. doi.org/10.23937/2643-4474/1710094

Accepted: January 12, 2022; Published: January 14, 2022

Copyright: (c) 2022 Ang YLS, et al. This is an open-access article distributed under the terms of the Creative Commons Attribution License, which permits unrestricted use, distribution, and reproduction in any medium, provided the original author and source are credited. 

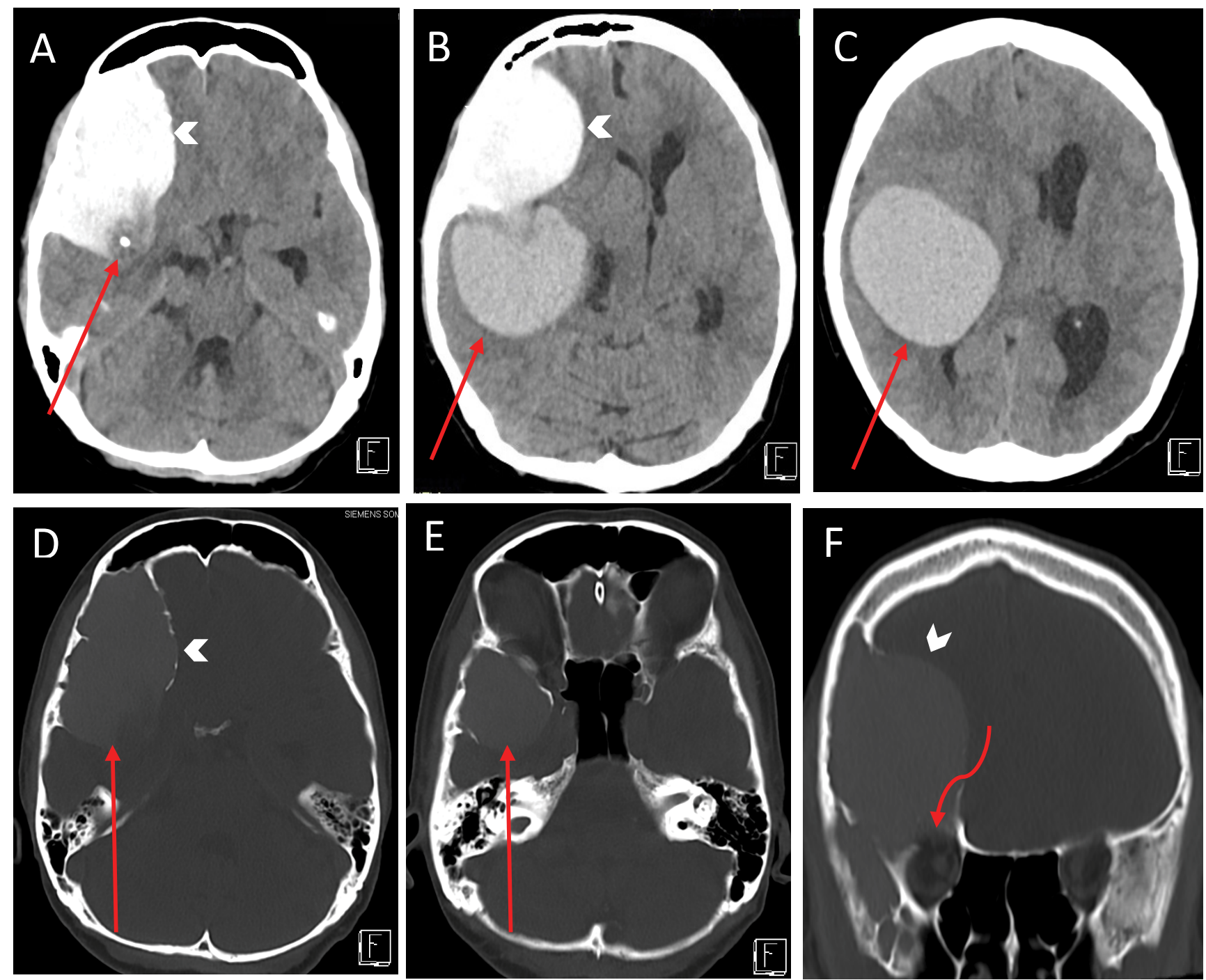

Figure 1: Axial non-contrast computed tomography (CT) head images (A-E) show a markedly hyperdense intradiploic lesion (arrow heads) scalloping the outer and inner tables of the right fronto temporal skull vault (D-E). There is a large hyperdense intraparenchymal lesion in the right frontal and temporal lobes (red arrows, in B and C). There is close contact between the intradiploic and intraparenchymal lesions (red arrows, D and E) with focal calcification at the junction between them (red arrow, A). The lesions cause significant mass effect with leftward shift of the midline structures and effacement of the right lateral ventricle. Coronal non-contrast CT head image (F) shows thinning of the inner table of the right frontal skull vault including the right anterior cranial fossa and the orbital roof (curved arrow).

change. She had no prior history of trauma. She also complained of long-standing blurred vision but did not experience any seizures nor any limb weakness or numbness. On examination, she was alert and oriented, and fundoscopic examination showed no papilloedema. The cranial nerves examination was unremarkable, and there was no evidence of any motor or sensory deficits in the extremities.

Computed tomography (CT) scan of the brain at the emergency department showed a markedly hyperdense right frontotemporal intradiploic lesion with scalloping of the overlying skull vault and orbital roof, as well as a large right intraparenchymal lesion just adjacent to the Sylvian fissure (Figure 1). Subsequent MRI revealed two large discrete masses containing varying proteinaceous content (Figure 2). The anterior extraaxial lesion measured $6.8 \times 4.4 \times 4.2 \mathrm{~cm}$, occupying the right anterior and middle cranial fossae, and expanding the greater wing of the right sphenoid bone. It was hyperintense on T1-weighted imaging, hypointense on T2-weighted imaging with susceptibility changes secondary to internal calcifications. The posterior lesion measured $5.1 \times 4.6 \times 5.8 \mathrm{~cm}$ and demonstrated isointensity on T2-weighted and hyperintensity on T1weighted sequences. Located in the right extra-axial temporal region and posterior to the Sylvian fissure, the lesion resulted in radial displacement of the underlying brain parenchyma. Both lesions did not show any postcontrast enhancement nor restricted diffusion. There was significant mass effect on the right frontotemporal lobes with mild perilesional oedema and leftward midline shift. There was effacement of the right lateral ventricle, with subfalcine and transtentorial herniations.

The patient was started on dexamethasone and antiepileptics, and planned for elective craniotomy and resection of both intracranial lesions. However, a day 

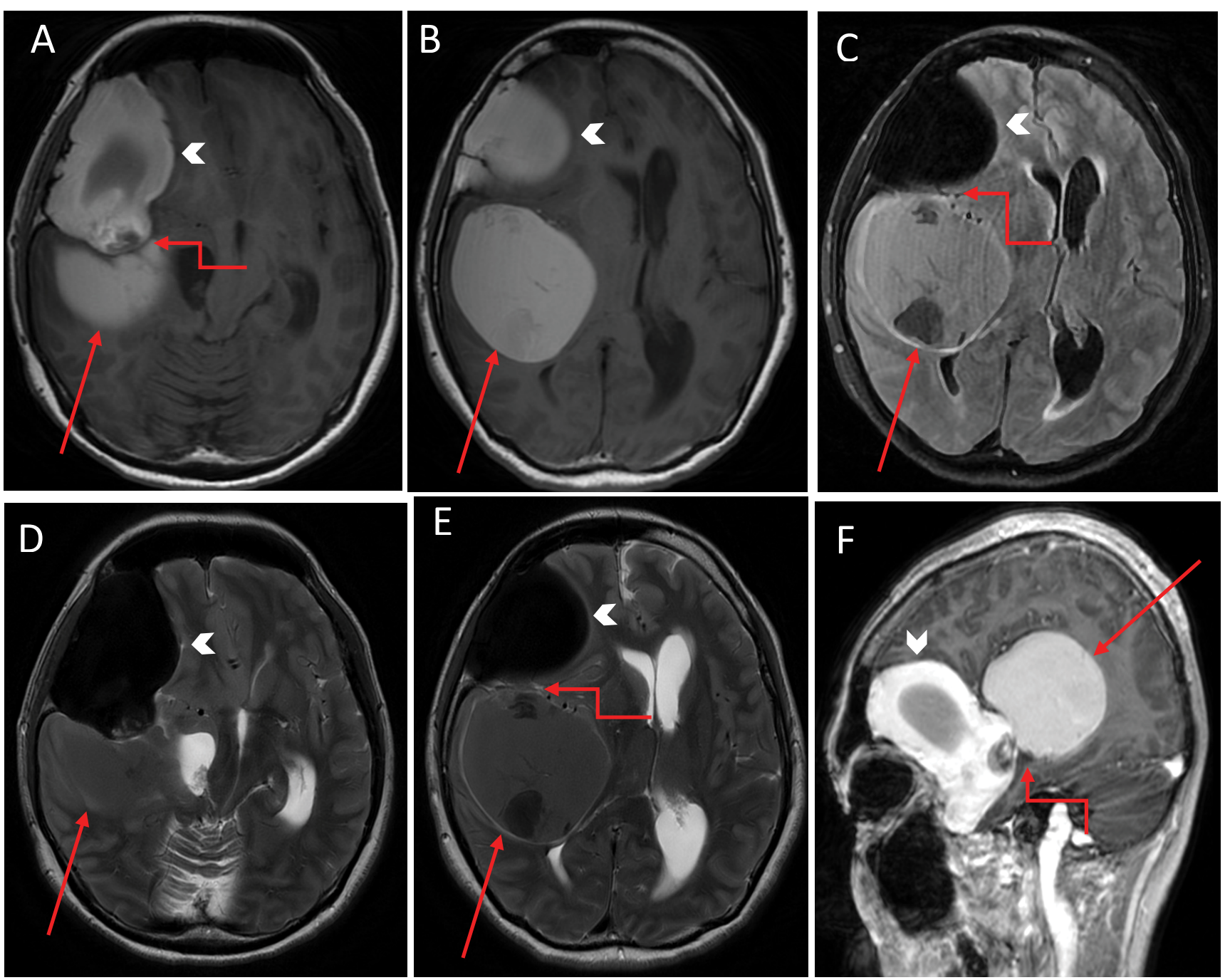

Figure 2: Axial non-contrast T1-weighted (A and B); FLAIR (C); T2-weighted (D and E) magnetic resonance (MR) images demonstrate intrinsic T1 hyperintense masses: A right frontotemporal intradiploic lesion (arrowhead) and a posteriorlysituated frontotemporal intraparenchymal lesion (red arrow). The intradiploic lesion shows marked T2 hypointensity while the intraparenchymal component shows mild T2 hypointensity (red arrows). The lesion causes significant mass effect with leftward shift of the midline structures and effacement of the right lateral ventricle. Sagittal T1-weighted post-contrast image (F) shows the two non-enhancing lesions closely abutting each other with focal calcification at the junction of contact (elbow connector arrow); Similar contact between the two components of the lesion are seen on the axial images (elbow connector arrow, $\mathrm{A}, \mathrm{C}$ and $\mathrm{E}$ ).

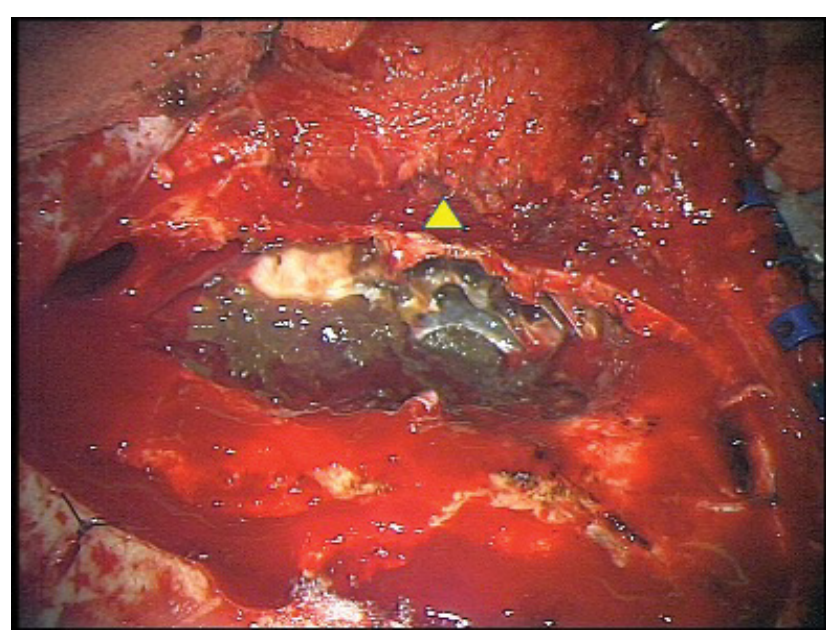

Figure 3: Intraoperative image of the extradural lesion, showing greyish-green gelatinous and pasty contents within the diploic space of the sphenoid bone with a thinned out sphenoid ridge (yellow triangle). before the planned surgery, she became acutely drowsy and was only able to localize pain with bilaterally brisk pupils (Glasgow Coma Scale of E3V2M5). An urgent repeat CT brain performed showed stable findings without any acute infarction, haemorrhage or increase in mass effect. In view of the clinical deterioration, she subsequently underwent emergency right craniotomy and excision of both lesions. A right frontotemporal craniotomy was performed. Upon lifting the bone flap, dark green, pasty, semi-solidified extradural contents partially contained within a thin transparent capsule were seen to be arising from within the bony matrix of the sphenoid ridge and temporal bone (Figure 3 ). There was also hyperostosis of the sphenoid ridge along with abnormal osseous growth along the floor of the anterior cranial fossa. After removal of these contents, a C-shaped durotomy was made based on the sphenoid ridge. An intradural extra-axial lesion was 


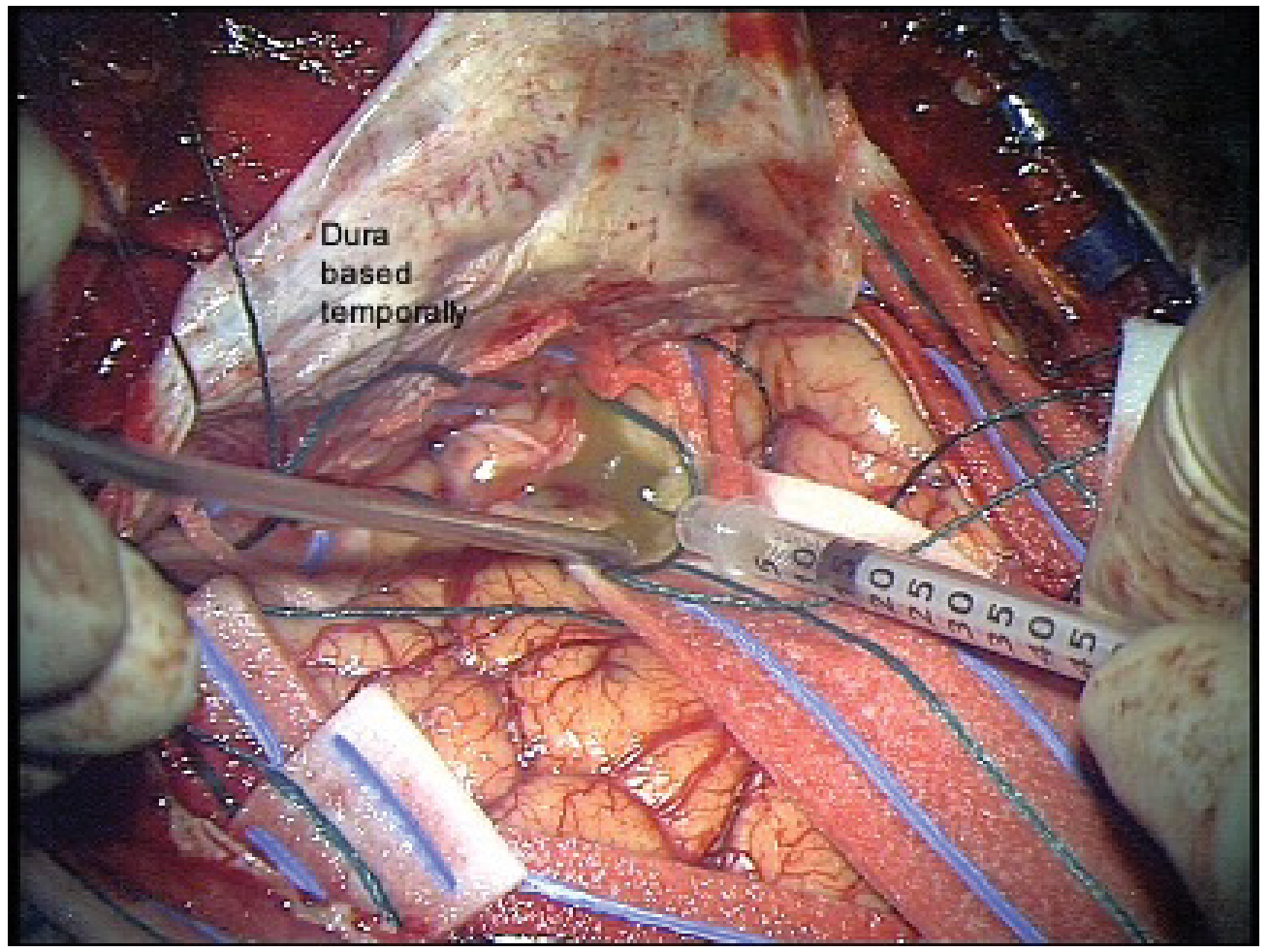

Figure 4: Intraoperative image after performing a C-shaped durotomy based temporally. The cystic lesion straddled the Sylvian fissure and contained viscous yellowish-green fluid and white keratin material within a thin transparent capsule.

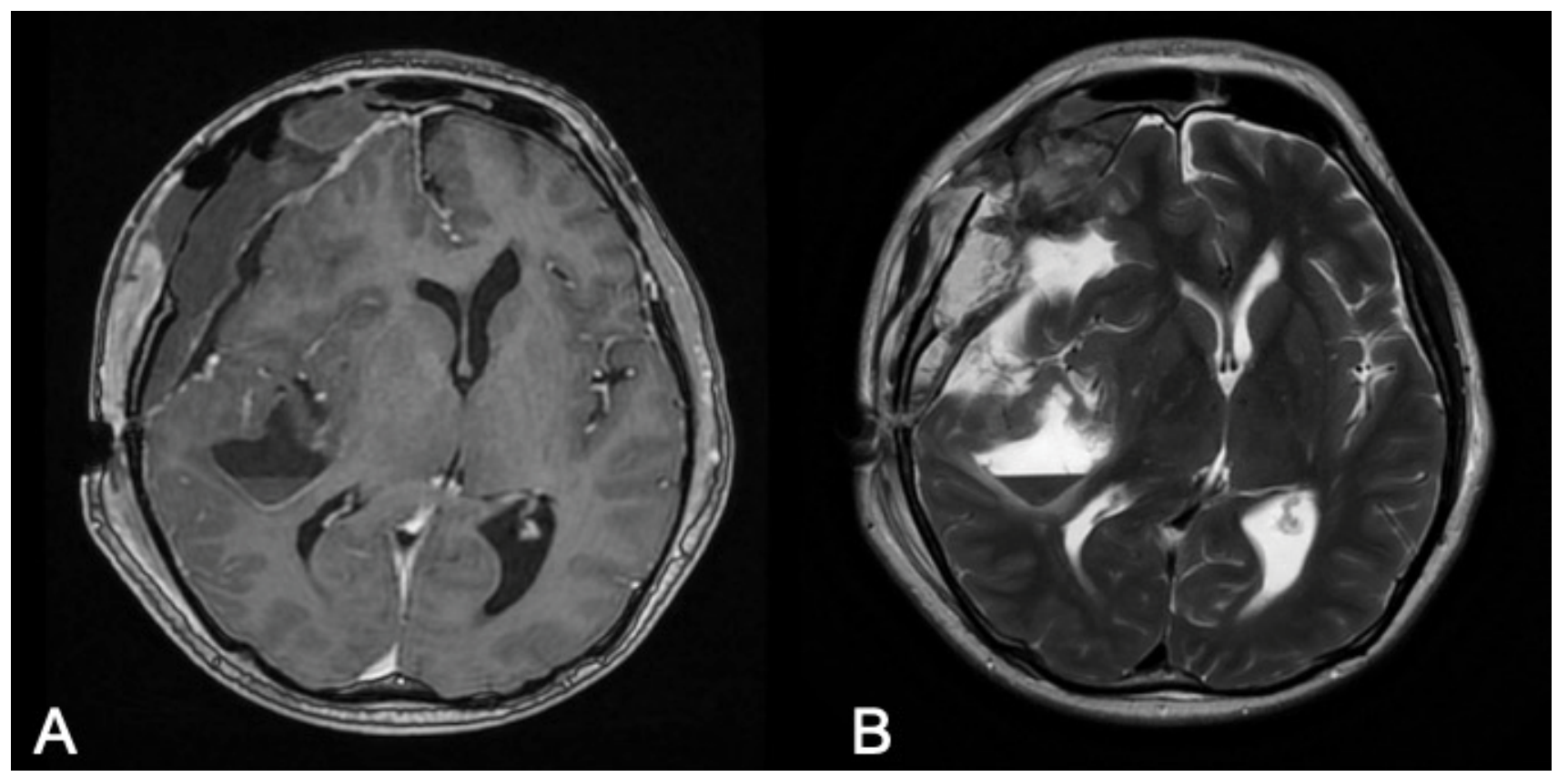

Figure 5: Postoperative contrasted T1-weighted (A); T2-weighted (B). MR images, demonstrating satisfactory excision of both large cystic lesions with a small amount of blood products in the surgical cavity with associated post-surgical changes. There is also improvement in the leftward midline shift with re-expansion of the right lateral ventricle.

noted within the right Sylvian fissure, containing pale yellowish-green, chalky fluid and white keratin pearls within a transparent capsule (Figure 4). The contents were gently aspirated to avoid spillage. The temporal portion of the cyst capsule was removed but the rest was firmly adherent to the underlying pial vessels and brain parenchyma, hence subtotal resection of the cyst was performed. Intraoperatively, the dura was intact between the two lesions indicating two anatomically separate lesions.

The patient improved neurologically and recovered well postoperatively with resolution of her headaches. Post-operative MRI showed satisfactory excision of both lesions with improvement of mass effect (Figure 5). Histology of the pasty extradural contents revealed cyst contents comprising abundant proteinaceous material 


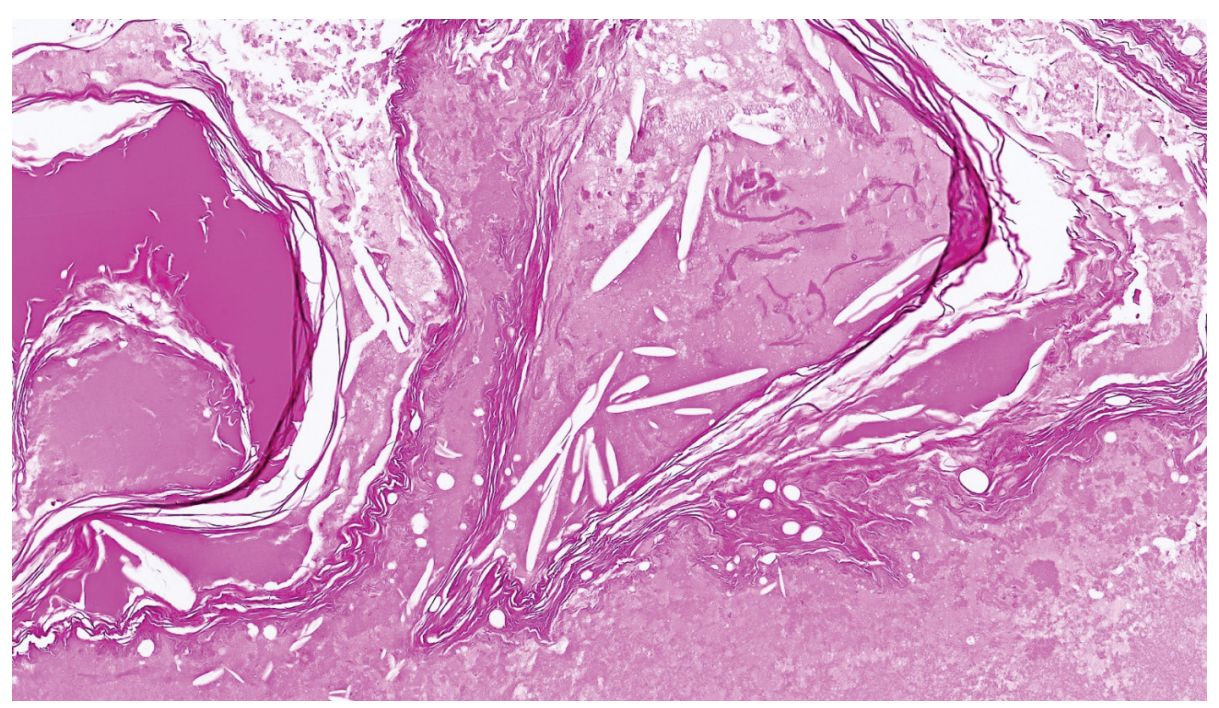

Figure 6: Extradural cyst contents featuring abundant proteinaceous material admixed with anucleate keratin and cholesterol clefts $(H \& E$, original magnification $\times 100)$.
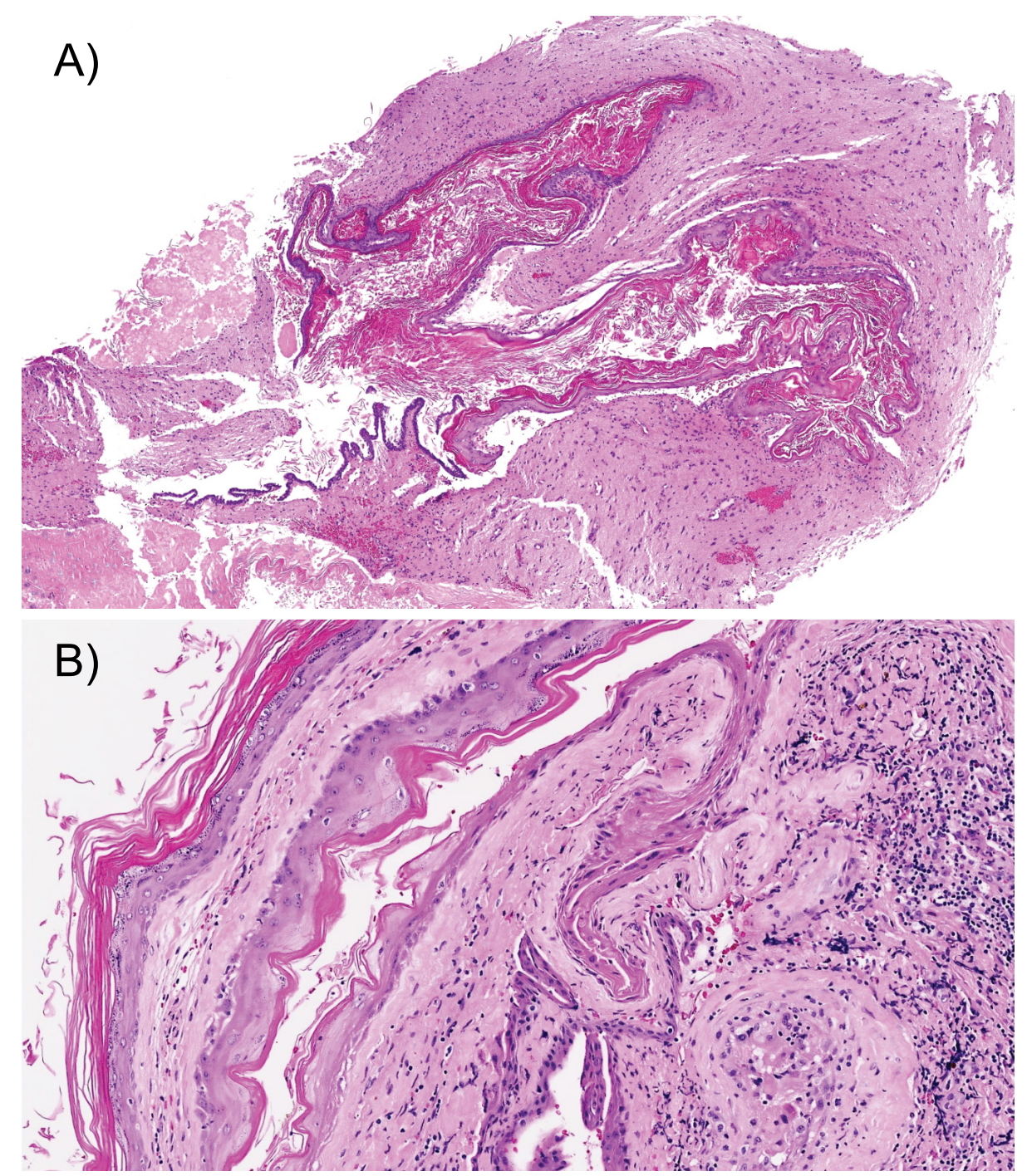

Figure 7: (a) Intradural component demonstrating an epidermoid cyst lined by benign stratified squamous keratinizing epithelium accompanied by cyst contents comprising keratin flakes and proteinaceous material (H\&E, original magnification $\times 40$ ); (b) Epidermoid cyst lined by benign stratified squamous keratinizing epithelium and adjacent brain parenchyma exhibiting gliosis and xanthogranulomatous inflammatory response to ruptured cyst contents (H\&E, original magnification $\times 100$ ). 
admixed with anucleate keratin and cholesterol clefts (Figure 6). The intradural component demonstrated portions of an epidermoid cyst lined by benign stratified squamous keratinizing epithelium accompanied by cyst contents comprising keratin flakes and proteinaceous material, without associated adnexal structures (Figure 7a). Adjacent areas demonstrated brain parenchyma with gliosis and a xanthogranulomatous inflammatory response to ruptured cyst contents (Figure $7 b$ ).

\section{Discussion}

Epidermoid cysts often possess a discrete thin outer capsule and a keratinised stratified squamous epithelial layer with inner cystic contents containing keratin pearls, cholesterol, tissue debris and proteinaceous fluid [8]. Proposed embryogenetic theories centre on the entrapment of ectodermal contents during various stages of neural tube closure. Intraparenchymal epidermoid cysts are purported to arise when the entrapment occurs before the primary cerebral vesicle is formed during the third week of embryogenesis, while intradiploic lesions occur when the entrapment occurs after neural tube closure [9-11]. However, the exact pathogenesis remains unclear.

The first case of intradiploic epidermoid cyst was reported by Harvey Cushing in 1922 [12]. Since then, multiple case reports have emerged [4,5,13,14-18], describing this rare entity that commonly presents as slowly enlarging scalp lumps. Our patient presented with insidious symptoms of raised intracranial pressure and was found to have two concomitant 'white epidermoid' cysts, one intradiplopic and the other intracerebral. Interestingly, both lesions were of different consistencies, with the former being mostly semi-solid and granular, while the latter was fluid in consistency.

In 2008, Ichimura, et al. reported a case with a dumbbell-shaped intracranial epidermoid cyst with extradural and intradural components that displayed typical MRI features. Intraoperatively, they found that the two components were contiguous via a dural defect [10]. Although there was contact between the intradiploic and intradural epidermoid cysts in our patient's scans, both the lesions were markedly different in terms of the CT and MRI features (Figure 2). Also, we did not identify any dural defect or direct communication between the intradiploic and intradural epidermoid lesions during surgery.

We propose that the lack of communication between the two epidermoid lesions could be due to a few theories. First, the entrapment of the ectodermal cells may have occurred within both the diploe and the Sylvian fissure along common radial lines of migration. It is known that embryologically, the anterior portion of the skull including the sphenoid bone constitutes the neurocranium which arises from neural crest cells [11].
The pre-migratory neural crest cells form the neural plate borders which separate non-neuroectodermal tissue from the neural plates. When the neural plates and neural crest cells from both sides converge, the non-neuroectodermal tissue could have been trapped within the fusion points of the neural plate and neural crest cell layers [1]. The two concomitant lesions seen in our patient could have therefore arisen from this entrapment process, albeit at different stages of neural tube closure. This theory may support the formation of the two discrete epidermoid lesions with varying proteinaceous contents in our patient's case. Alternatively, both epidermoid lesions could have been originally connected via a dural defect with subsequent healing or fibrosis as a result of inflammatory reactions from the cystic contents. Consequently, the intradiploic epidermoid cyst underwent cycles of calcification and resorption, resulting in a paste-like, semi-solid contents found intraoperatively. Conversely, the walled-off and discrete intracerebral epidermoid component persisted as thick viscous fluid contents, explaining the different consistencies of the two epidermoid cysts. latrogenic or traumatic ectodermal cell implantation leading to two discrete epidermoid cysts is a less likely postulation given that our patient had no prior history of traumatic head injury or invasive intracranial procedures.

The radiological features of the 'white epidermoid' (intrinsic CT hyperdensity and T1 hyper- and T2 hypointensities on MRI) have been postulated by some authors to be related to its high protein content which can be secondary to recurrent inflammatory reactions incited by chemicals within the cyst content $[3,9]$. This appearance corresponded to an intraoperative observation of thick viscous 'toffee-like' contents that required removal by a 'spatula'. Similar observations have been reported by other authors [15].

One of the complications related to 'white epidermoids' was chemical irritation or aseptic meningitis due to seepage or spillage of cyst contents into the subarachnoid space [15]. This could have been the cause of our patient's acute neurological deterioration as repeat imaging did not show any change in the size of both lesions or the amount of mass effect. Moreover, histology also showed evidence of xanthogranulomatous inflammation of the adjacent brain parenchyma in response to ruptured cyst contents.

In the largest series of atypical epidermoids, Ren, et al. [19] described neovascularisation from inflammation as a cause of intracranial haemorrhage that could potentially perpetuate the inflammatory process. This process could also explain the reason for the adherence of the epidermoid cyst wall to the surrounding structures, making it difficult to achieve complete resection. In this paper, we also performed a literature review on reports and series looking at epidermoid cysts with atypical imaging features (Table 1). We found that 
Table 1: Characteristics of cases reported in literature with atypical appearance of epidermoid cysts on MRI.

\begin{tabular}{|c|c|c|c|c|c|c|c|c|}
\hline \multirow[t]{3}{*}{ Reference (n) } & \multicolumn{4}{|c|}{$\begin{array}{c}\text { Additional Radiological } \\
\text { Features }\end{array}$} & \multirow{3}{*}{$\begin{array}{l}\text { Patient } \\
\text { Demographics } \\
\text { (Age/Gender) }\end{array}$} & \multirow[t]{3}{*}{ Site } & \multirow[t]{3}{*}{ Symptoms } & \multirow{3}{*}{$\begin{array}{l}\text { Adherence; } \\
\text { Extent of } \\
\text { Resection }\end{array}$} \\
\hline & \multicolumn{3}{|c|}{ Enhancement } & \multirow{2}{*}{$\begin{array}{l}\text { Restricted } \\
\text { Diffusion }\end{array}$} & & & & \\
\hline & Yes & No & NOS & & & & & \\
\hline $\begin{array}{l}\text { Hamouda, et al. [6] } \\
(n=1)\end{array}$ & - & 1 & - & No & 50/Female & CPA & $\begin{array}{l}\text { Diplopia, Gait } \\
\text { Instability }\end{array}$ & NOS; GTR \\
\hline $\begin{array}{l}\text { Lian, et al. [17] } \\
(n=1)\end{array}$ & - & 1 & - & No & 45/Male & Frontal Lobe & Seizures & Adherent, STR \\
\hline $\begin{array}{l}\text { Law, et al. [15] } \\
(n=1)\end{array}$ & - & 1 & - & No & 47/Male & Cerebellum & $\begin{array}{l}\text { Headache, } \\
\text { Ataxia }\end{array}$ & NOS; GTR \\
\hline $\begin{array}{l}\text { Prasad, et al. [2] } \\
(n=1)\end{array}$ & 1 & - & - & Yes & 65/Female & Sellar & $\begin{array}{l}\text { Visual Loss, } \\
\text { Diabetes } \\
\text { Insipidus }\end{array}$ & NOS; STR \\
\hline \multirow[t]{5}{*}{$\begin{array}{l}\text { Li, et al. [16] } \\
(n=5)\end{array}$} & \multirow[t]{5}{*}{1} & \multirow[t]{5}{*}{1} & \multirow[t]{5}{*}{3} & NOS & 29/Female & Parasellar & $\begin{array}{l}\text { Headache, } \\
\text { Facial } \\
\text { Paraesthesia }\end{array}$ & Adherent; STR \\
\hline & & & & No & 49/Female & Clival & Hearing Loss & NOS; STR \\
\hline & & & & NOS & 26/Female & Cerebellum & $\begin{array}{l}\text { Headache, } \\
\text { Vomiting }\end{array}$ & NOS; GTR \\
\hline & & & & NOS & 27/Female & Clival & $\begin{array}{l}\text { Headache, } \\
\text { Unsteady Gait }\end{array}$ & NOS; GTR \\
\hline & & & & NOS & 46/Female & Clival & Limbic Paralysis & NOS; GTR \\
\hline \multirow{24}{*}{$\begin{array}{l}\text { Ren, et al. }(2012)^{*} \\
{[19](n=24)}\end{array}$} & \multirow[t]{24}{*}{5} & \multirow[t]{24}{*}{19} & \multirow[t]{24}{*}{-} & \multirow[t]{24}{*}{ NOS } & 34/Male & CPA, Sellar & \multirow[t]{24}{*}{ NOS } & Adherent, STR \\
\hline & & & & & 30/Female & $\begin{array}{l}\text { CPA, Sellar, } \\
\text { Prepontine Cistern }\end{array}$ & & Adherent, GTR \\
\hline & & & & & 58/Female & Frontal Lobe & & Not Adherent, GTR \\
\hline & & & & & 24/Female & Cerebellum & & Adherent, GTR \\
\hline & & & & & 28/Female & Parasellar & & Adherent, GTR \\
\hline & & & & & 40/Female & Sellar & & Not Adherent, STR \\
\hline & & & & & 38/Female & CPA, Parasellar & & Not Adherent, STR \\
\hline & & & & & 30/Female & Parasellar & & Adherent, STR \\
\hline & & & & & 42/Male & Parasellar & & Not Adherent, GTR \\
\hline & & & & & 37/Female & CPA & & Adherent, STR \\
\hline & & & & & 45/Male & CPA & & Adherent, STR \\
\hline & & & & & 37/Male & Temporal Lobe & & Adherent, STR \\
\hline & & & & & 40/Male & Temporal Lobe & & Adherent, GTR \\
\hline & & & & & 36/Male & Parietal Lobe & & Not adherent, GTR \\
\hline & & & & & 43/Female & Parasellar & & Adherent, STR \\
\hline & & & & & 30/Male & CPA & & Adherent, STR \\
\hline & & & & & 39/Female & Parasellar & & Adherent, GTR \\
\hline & & & & & 31/Male & Frontal Lobe & & Adherent, GTR \\
\hline & & & & & 27/Male & CPA, Parasellar & & Adherent, GTR \\
\hline & & & & & 63/Male & Parafalcine & & Adherent, GTR \\
\hline & & & & & 33/Male & Parasellar & & Adherent, STR \\
\hline & & & & & 43/Female & Cerebellum & & Not Adherent, GTR \\
\hline & & & & & 46/Male & Parasellar & & Adherent, GTR \\
\hline & & & & & 46/Female & CPA, Parasellar & & Not Adherent, GTR \\
\hline \multicolumn{8}{|c|}{ Total number of cases: 33} & $\begin{array}{l}\text { Adherent (19/33); } \\
\text { GTR (19/33) } \\
\text { STR (14/33) }\end{array}$ \\
\hline
\end{tabular}

$\mathrm{n}$ : Number of patients with atypical epidermoid cysts reported in the study; NOS: Not Otherwise Specified; CPA: Cerebellopontine Angle; GTR: Gross Total Resection; STR: Subtotal Resection; "Study did not report specific MRI features for each case. 
gross total resection (GTR) was achieved in 19 out of $33(57.6 \%)$ cases. The rest had subtotal resection (STR) as the cyst capsule was found to be adherent. This GTR rate is comparable to that reported in a 2019 systematic review [20], which looked at the extent of resection in 691 patients with epidermoid tumours. In that review, 293 (42\%) underwent subtotal resection (STR) and 398 (58\%) received GTR. Of note, STR was associated with 7 times higher risk of recurrence compared to GTR [20]. Despite this, aggressive dissection may not be advisable [21], especially since epidermoid cysts are deemed to have a slow linear growth rate similar to epithelial cells, with one generation per month [22].

\section{Conclusion}

We have described an interesting case of a symptomatic patient with simultaneous occurrence of two large and discrete intracranial 'white epidermoid' cysts, one intradiploic and the other intracerebral. To our knowledge, there has not been any report in the literature of multifocal large 'white epidermoid' cysts. Theories based on the embryological origin of these epidermoid cysts may explain the concomitant occurrence of these lesions. We suggest that in patients with seemingly discrete lesions displaying atypical imaging features of epidermoid cysts, one should consider 'white epidermoid' tumours in the differential diagnoses. It is imperative to be aware of the complications and recurrence risks of these relatively benign lesions. Further research into the pathophysiology and their respectability as well as the long-term recurrence rates of these atypical epidermoid cysts would be useful to guide patient treatment and follow-up surveillance.

\section{Disclosure}

The authors declare that the article content was composed in the absence of any commercial or financial relationships that could be construed as a potential conflict of interest.

\section{Informed Consent}

Informed written consent was obtained from the patient for the publication of this work.

\section{References}

1. Osborn AG, Preece MT (2006) Intracranial cysts: Radiologicpathologic correlation and imaging approach. Radiology 239: $650-664$

2. Prasad GL, Pavithra P (2017) Suprasellar epidermoid cyst with atypical imaging findings. World Neurosurg 98: 870 . e1-870.e3.

3. Aribandi M, Wilson NJ (2008) CT and MR imaging features of intracerebral epidermoid--a rare lesion. $\mathrm{Br} \mathrm{J}$ Radiol 81: e97-e99.

4. Chen C-Y, Wong J-S, Hsieh S-C, Chu J-S, Chan WP (2006) Intracranial epidermoid cyst with hemorrhage: MR imaging findings. AJNR Am J Neuroradiol 27: 427-429.
5. Katzman GL (2004) Epidermoid cyst. In: Diagnostic imaging: Brain. Salt Lake City, Amirsys, Utah.

6. Ben Hamouda M, Drissi C, Sebai R, Hammami N, Ghorbel D, et al. (2007) Atypical CT and MRI aspects of an epidermoid cyst. J Neuroradiol 34: 129-132.

7. Bihan D, Poupon C, Amadon A, Lethimonnier F (2006) Artifacts and pitfalls in diffusion MRI. J Magn Reson Imaging 24: 478-488.

8. Recinos PF, Roonprapunt C, Jallo Gl (2006) Intrinsic brainstem epidermoid cyst. Case report and review of the literature. J Neurosurg 104: 285-289.

9. Gosal J, Joseph J, Khatri D, Das KK, Jaiswal A, et al. (2019) White Epidermoid of the sylvian fissure masquerading as a dermoid cyst: An extremely rare occurrence. Asian J Neurosurg 14: 553-556.

10. Ichimura S, Hayashi T, Yazaki T, Yoshida K, Kawase T (2008) Dumbbell-shaped intradiploic epidermoid cyst involving the dura mater and cerebellum. Neurol Med Chir (Tokyo) 48: 83-85.

11. Kaido T, Okazaki A, Kurokawa S, Tsukamoto M (2003) Pathogenesis of intraparenchymal epidermoid cyst in the brain: A case report and review of the literature. Surg Neurol 59: 211-216.

12. Cushing $H$ (1922) A large epidermal cholesteatoma of the parietotemporal region deforming the left hemipshere without cerebral symptoms. Surg Gynecol Obstet 34: 557566 .

13. Dabrowski P, Kidzinski R, Frankowska E, Gorski R, Bujko M (2018) Intradiploic epidermoid cyst of the temporal and occipital bone with intracranial extension. Neurol Neurochir Pol 52: 756-758.

14. Khalid S, Khan SA, Aurangzeb A, Muhammad G, Khan Afridi EA, et al. (2021) Intradiploic epidermoid cyst of the skull. J Ayub Med Coll Abbottabad 33: 349-351.

15. Law EK, Lee RK, Ng AW, Siu DY, Ng HK (2015) Atypical intracranial epidermoid cysts: Rare anomalies with unique radiological features. Case Rep Radiol 2015: 528632.

16. Li F, Zhu S, Liu Y, Chen G, Chi L, et al. (2007) Hyperdense intracranial epidermoid cysts: A study of 15 cases. Acta Neurochir (Wien) 149: 31-39.

17. Lian K, Schwartz ML, Bilbao J, Perry J, Aviv RI, et al. (2012) Rare frontal lobe intraparenchymal epidermoid cyst with atypical imaging. J Clin Neurosci 19: 1185-1187.

18. Ma J, Jia G, Jia W (2019) Primary intradiploic epidermoid cyst: A case report with literature review. Clin Neuropathol 38: 28-32.

19. Ren X, Lin S, Wang Z, Luo L, Jiang Z, et al. (2012) Clinical, radiological, and pathological features of 24 atypical intracranial epidermoid cysts. J Neurosurg 116: 611-621.

20. Shear BM, Jin L, Zhang Y, David WB, Fomchenko El, et al. (2019) Extent of resection of epidermoid tumors and risk of recurrence: Case report and meta-analysis. J Neurosurg 5: $1-11$.

21. Tatagiba M, laconetta G, Samii M (2000) Epidermoid cyst of the cavernous sinus: Clinical features, pathogenesis and treatment. Br J Neurosurg 14: 571-575.

22. Collins VP, Loeffler RK, Yivery H (1956) Observations on growth rates of human tumors. Am $\mathrm{J}$ Roentgenol Radium Ther Nucl Med 76: 988-1000.
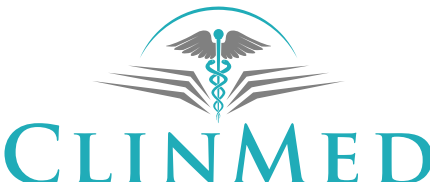

INTERNATIONAL LIBRARY 